\title{
Optimal Siting of Distributed Generation Unit in Power Distribution System considering Voltage Profile and Power Losses
}

\author{
Muhammad Aamir Aman $\mathbb{D}^{1},{ }^{1}$ Xin Cheng Ren $\mathbb{D}^{\mathrm{D}},{ }^{2}$ Wajahat Ullah Khan Tareen, ${ }^{3}$ \\ Muhammad Abbas Khan, ${ }^{4}$ Muhammad Rizwan Anjum (D), ${ }^{5}$ Anas M. Hashmi, ${ }^{3}$ \\ Haider Ali $\mathbb{D}$, ${ }^{6}$ Inam Bari $\left(\mathbb{D},{ }^{7}\right.$ Jehanzeb Khan $\left(\mathbb{D},{ }^{1}\right.$ and Sanaullah Ahmad ${ }^{1}{ }^{1}$ \\ ${ }^{1}$ Department of Electrical Engineering, Iqra National University, Peshawar 25000, Pakistan \\ ${ }^{2}$ School of Physics and Electronic Information, Yanan University, Yanan 761000, China \\ ${ }^{3}$ Department of Electrical and Electronic Engineering, College of Engineering, University of Jeddah, Jeddah 21589, Saudi Arabia \\ ${ }^{4}$ Department of Electrical Engineering, Balochistan University of Information Technology (FICT), \\ Engineering and Management Sciences, Quetta, Pakistan \\ ${ }^{5}$ Department of Electronic Engineering, The Islamia University of Bahawalpur, Bahawalpur 63100, Pakistan \\ ${ }^{6}$ Department of Electrical and Electronics Engineering Technology, University of Technology, Nowshera 24100, Pakistan \\ ${ }^{7}$ Systems Engineering Department, Military Technological College, Muscat, Oman
}

Correspondence should be addressed to Muhammad Aamir Aman; aamiraman@inu.edu.pk and

Xin Cheng Ren; xchren@yau.edu.cn

Received 31 October 2021; Accepted 17 December 2021; Published 10 January 2022

Academic Editor: Muhammad Faisal Nadeem

Copyright (c) 2022 Muhammad Aamir Aman et al. This is an open access article distributed under the Creative Commons Attribution License, which permits unrestricted use, distribution, and reproduction in any medium, provided the original work is properly cited.

\begin{abstract}
Many underdeveloped countries are facing acute shortage of electric power and short term measures are important to consider to address the problems of power outage, power plant failures, and disaster areas. Distributed generation (DG) is a promising approach for such cases as it allows quick on-site installation and generation of electric power. Injection of DG can improve the system voltage profile and also reduce the system's total power losses. However, the placement and sizing of the DG unit is an optimization problem in the radial distribution system. As a test case, this study examines voltage profile improvement and system power losses for an $11 \mathrm{KV}$ residential feeder at the Abdul Rehman Baba grid station in Pakistan, which is modelled using the Electrical Transient Analyzer Program (ETAP). For various scenarios, several tests are conducted to assess the effects of DG on the distribution system. The results show that proper design considerations of size and location of a DG, to be inserted in to the system, lead to significant reduction in power losses and improvement in voltage profile and thus improvement in the overall efficiency of the power system. The projections of this work can be used to optimize the expansion of a power system and tackling different issues related to voltage profile in distribution sector worldwide.
\end{abstract}

\section{Introduction}

The flow of electric power from a generating station to the load premises is typically controlled by three subsystems connected to the generation, transmission, and distribution of electricity [1]. Different types of producing power facilities, such as hydropower plants, thermal power plants, and nuclear power plants, are employed to meet the ever-increasing demand for electric power by industrial and home consumers. Conventional power plants are often built in a remote location far away from the consumer load $[2,3]$. Power is transmitted from the generating station to the distributed load via transmission lines and feeders. Figure 1 depicts an electrical producing station, followed by a transmission system, and, finally, a distribution system. However, due to a variety of factors, a significant amount of generated electricity is lost. 


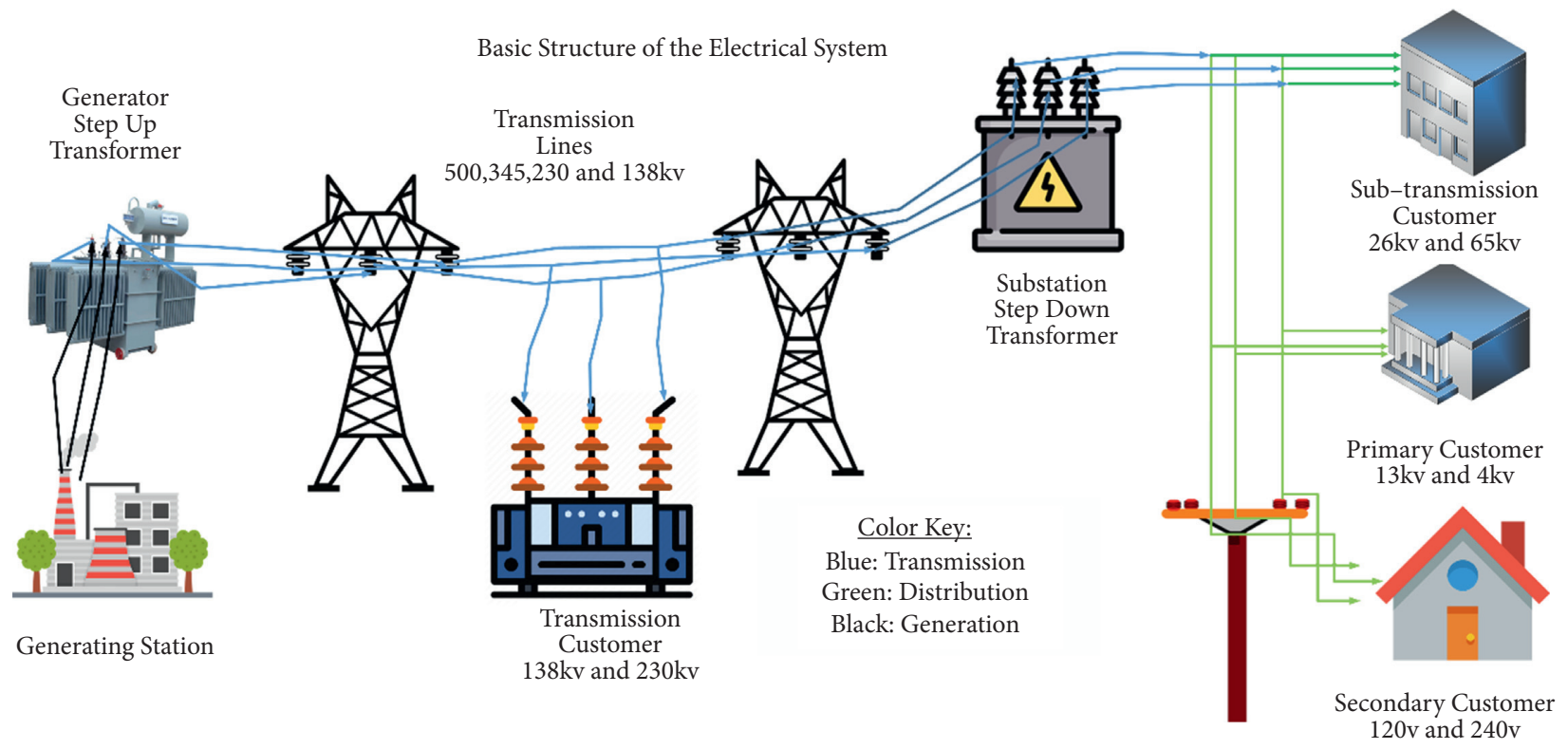

FIGURE 1: Electrical power system performing generation, transmission, and distribution [3].

Electricity demand is increasing at a pace of 1.40 percent per year, according to energy data sources [4]. The energy department of the United States of America has disclosed that fossil fuels account for 78.40 percent of overall electricity generation. Nuclear power generates about 2.60 percent of total electrical energy, whereas nonconventional sources such as geothermal, wind, and solar power contribute about 19.0 percent, as shown in Figure 2 [5].

Increase in power generation through fossil fuels is not practical since their existence is limited and emission of harmful gases and wastes from fossil fuels for the generation of electrical energy are not environment friendly. Development of new non-fossil fuel power plant, such as hydro or nuclear one, requires considerable amount of time and huge budgets [6]. Keeping in view these facts, the desperate need of the hour is to optimize the currently installed power generation systems to reduce the power losses (PLs) and improve voltage profile, which will effectively reduce the demand on power generation units within no time. As a result, this study examines the impact of distribution system components on PLs and voltage profile improvement as a result of DG injection, with the goal of lowering PLs and increasing system efficiency. To validate the proposed optimization strategy, the electrical transient analyzer software (ETAP) is utilised to run simulations based on the real acquired data from the grid station. A six-bus-bar distribution system is chosen as a test case, and ETAP is used to model and analyze it. A synchronous generator and an induction generator are used as DG units in two circumstances.

1.1. Related Work. Distributed generations (DG) development is presented throughout the entire globe in two levels, i.e., with the advancement in Research and Development $(\mathrm{R} \& \mathrm{D})$ and DG's project expansion using Scopus database
Figure 3. This shows the rapid increase in the research work published using optimization techniques in DG's deployment from renewable energy resources during the last decade. Growth in DG's installation has also been noticed accompanying the evaluation in publishing research work.

The key carter behind the growth of DGs from renewable energy resources can be characterized into four core classes, i.e., environmental driver, economical driver, technological driver, and technical driver. The expansion of DGs introduces various benefits behind these drivers but it results in some challenges like economic and technical ones from the integration of DGs aggressively. This will affect the grid stability and power system quality as the flow of power changes from unidirectional to bidirectional with a definite voltage level. Thus the choice of DG injected capacity not only is dependent on the cost and benefit but also will be dependent on the optimized location and size to maintain reduction of high power losses in the system. Literature depicts many optimization methods like conventional and intelligent search methods to solve energy problems. A wide range of optimization techniques is used so far. Classification of these methods is illustrated as follows: analytical based method, gradient and second-order method, iterative method, and heuristic methods. Conventional methods are very effective but tough in the implementation of real-size problems and require too much computing time, while heuristic methods are founded on simplifying the problem and contributing adequate solutions [6]. In distributed generation system, the power has radial structure and unidirectional behaviour which is severely affected by the increase in demand and negative impacts on voltage profile and causes PLs at the transmission network, as well as in distribution networks. Various approaches have been suggested till date to mitigate PLs such as in [7], where authors have developed an analytical expression to estimate the optimal size for distribution networks (DNs) with different 


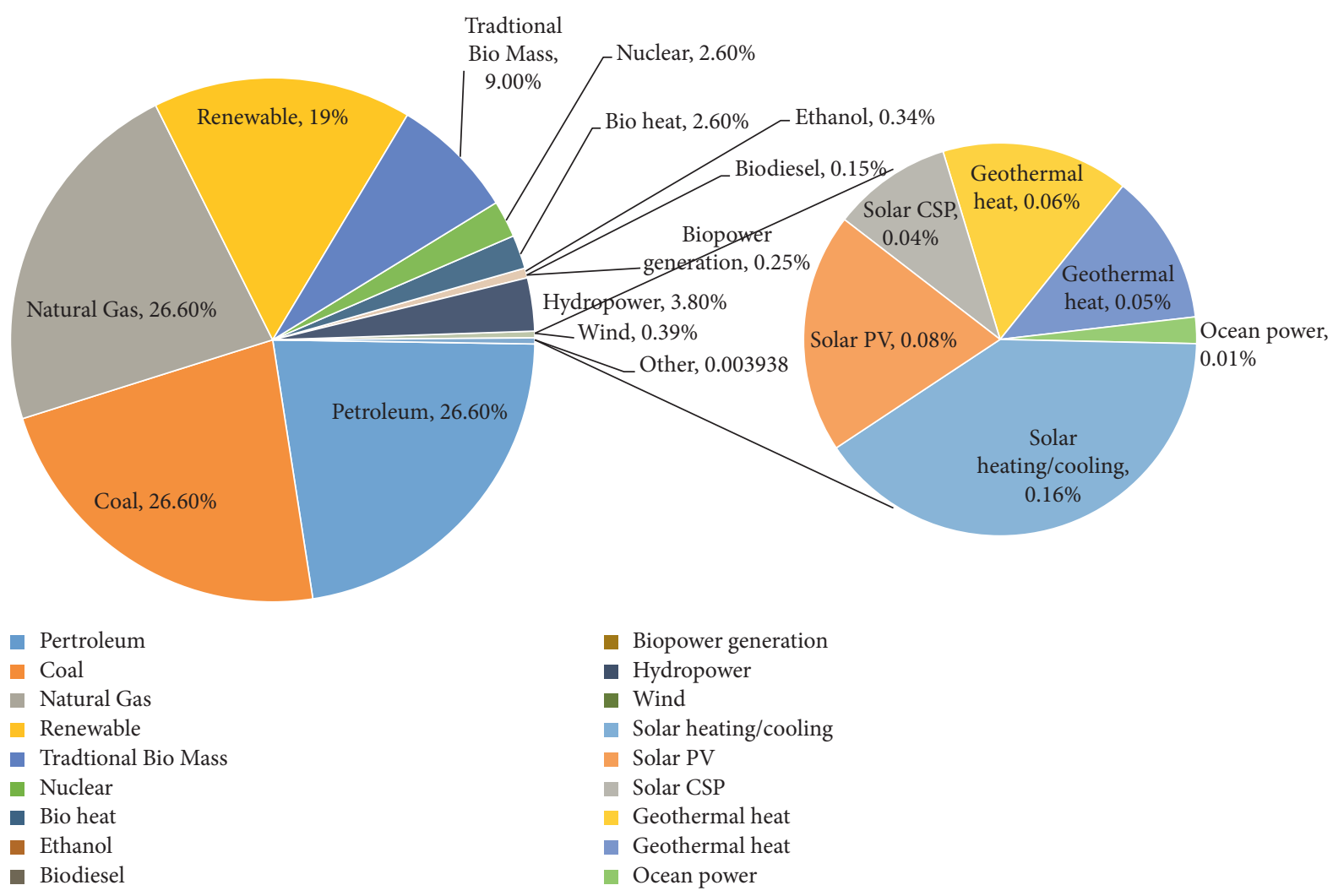

FIGURE 2: Distribution of power generation from various sources [5].

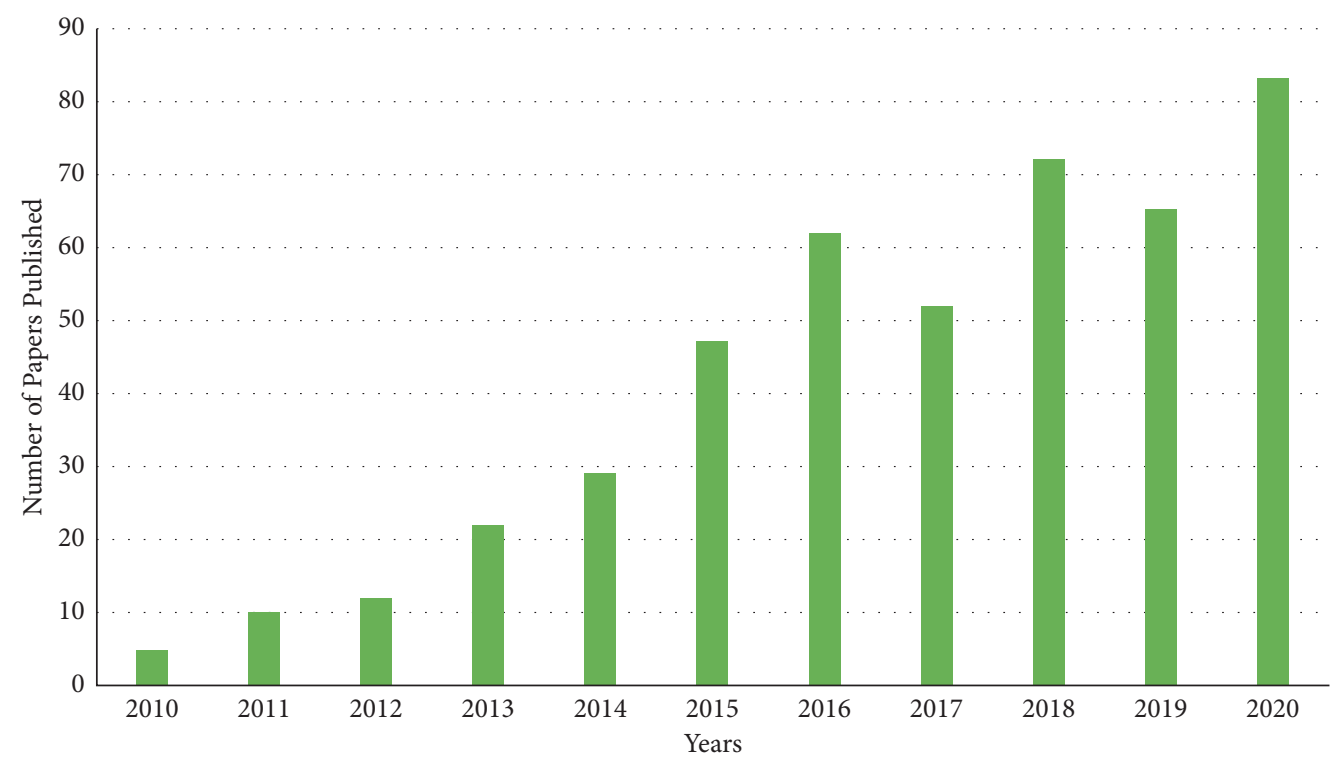

FIGURE 3: Research papers published during the last decade using optimization techniques used in deployment DGs from renewable energy resources.

PL arrangements. Another procedure in [8] discusses optimization algorithms for reducing PLs in DNs while [9] explains shuffled frog leaping algorithm to analyzed PLs and optimal sizing of DNs. The optimal distribution sizing and PLs have been also investigated in [10] using elephant herding optimization method and in [11] with an estimation through adaptive neurofuzzy logic. However, the proposed techniques require complex structure for the analysis. A low complexity approach using two-bus Thevenin equivalent model to improve power quality is DNs which has been shown in [12]; however none of them provides proper analysis for the sizing and optimum location for optimization process. In this paper, we explore sizing and optimum location considering voltage profile improvement and 
minimization of PLs based on the experimental data acquisition from the Abdul Rehman Baba grid station, Pakistan, and analysis in ETAP.

1.2. Paper Contribution. In this paper, we present an optimal siting for integration of DGs in DNs to improve voltage profile and to minimize PLs not only to address the issue of power shortage faced by many underdeveloped countries, but also to assist power design engineers in analysis of such systems. The main contributions of proposed work are as follows:

(1) The proposed technique is investigated for DGs based on voltage profile improvement and PLs reduction for $11 \mathrm{KV}$ residential feeder.

(2) A mathematical model is developed for DG based on the experimental data acquisition.

(3) The best optimum size and possible location of DG unit are evaluated for enhancing the voltage profile of the distribution system.

(4) Synchronous and induction generators are used as DG units in the simulations to widen the scope of analysis. The system is analyzed for operation at various conditions, like without DG unit, with synchronous DG unit, and with an induction DG unit.

(5) In addition, this research work is extended by performing analysis for different bus-bars and power factors.

(6) The results show that the synchronous generator DG unit has better performance than induction generator DG unit as the PLs due to the standalone integration of induction generator are even more than the system with no additional DG unit at all.

1.3. Paper Organization. The remaining part of the paper is organized as below. Section 2 elaborates the distributed generation implications on DNs and the proposed approach for improvement of voltage profile and reduction of PLs caused by injecting a DG. Section 3 explains the mathematical modelling of the proposed work. Section 4 presents test feeder analysis and explores DG units modelling in terms of synchronous and induction generators. Results and discussion are presented in Section 5, and the paper is concluded in Section 6.

\section{Implications of Distributed Generation Integration with Distribution System}

Although DG injection has a variety of effects on the electrical power system, it remains an appealing option for future power systems due to its plug-and-play nature, flexibility of operation, and other benefits. The main feature of connecting DG is the enhancement of overall efficiency of the electrical power system without making significant changes to the existing infrastructure. The transmission loss of electricity in its transport over long distances is usually from 4.20 to $8.90 \%$ of the transmitted electricity due to different factors such as reactive nature of various components, connection losses, bulk resistance, etc. Similarly, in addition to the cost of generation, utilities charge customers for the cost of electricity lost owing to transmission from distant generating units. These expenses can be reduced by putting DG close to the load location. Integrating a DG unit into the system can also aid in peak shaving and power stability reduction [13-16]. Where voltage dips and blackouts are an issue for service providers, DG injection can help reduce power losses and improve voltage profile. The flow of electricity is usually one-way, from the generator to the load, but by introducing DG into the distribution system, the flow of power can be bidirectional. Injection of DG can reduce power losses in areas where service providers are concerned about voltage dips and blackouts. Distributed generation implementation can enhance the voltage profile of electric service in the distribution system. Improvement in voltage profile depends upon the size, type, and suitable siting of DG unit in a distribution network. If the DG unit is not injected in a suitable place, it could provoke a negative impact on voltage profile, power losses, and operation of the system. For this purpose, different optimization methods are taken into consideration to settle the optimal location and size of the distributed generation unit to upgrade the performance of the distribution system [17-20]. The DG unit is injected on the location after the analysis of identifying node with maximum power losses. Because power losses differ depending on the type of DG employed and the location of DG installation, an overall optimization is obtained, which is discussed mathematically in the next section.

\section{Mathematical Modelling}

Different iterative techniques are used for the solution of power flow equations but Newton Raphson method [21, 22] has some distinct features of numerical analysis and has lowest complexity. In this particular method, two equations with two unknown variables like $\mathrm{Y}_{1}$ and $\mathrm{Y}_{2}$ are solved through quick approximation of the root of a real-valued function. Take two working variables, such as $\mathrm{Y}_{1}$ and $\mathrm{Y}_{2}$, and set them equal to $B_{1}$ as

$$
G_{1}\left(Y_{1}, Y_{2}\right)=B_{1} \text {. }
$$

In the same way,

$$
G_{2}\left(Z_{1}, Z_{2}\right)=C_{2}
$$

It is also written as

$$
\begin{aligned}
& B_{1}=G_{1}\left(Y_{1}, Y_{2}\right)=G_{1}\left(Y_{1}{ }^{(0)}+\Delta Y_{1}{ }^{(0)}, Y_{2}+\Delta Y_{2}{ }^{(0)}\right) . \\
& B_{2}=G_{2}\left(Y_{1}, Y_{2}\right)=G_{2}\left(Y_{1}{ }^{(0)}+\Delta Y^{(0)}, Y_{2}+\Delta Y^{(0)}\right) .
\end{aligned}
$$

The difficulty now is to find a solution for $\Delta Y_{1}{ }^{(0)}$ and $\Delta Y_{2}{ }^{(0)}$. 
Expanding equations (3) and (4),

$$
\begin{aligned}
& B_{1}=G_{1}\left(Y_{1}{ }^{(0)}, Y_{2}{ }^{(0)}\right)+\left.\Delta Y_{1}{ }^{(0)} \frac{\partial G_{1}}{\partial Y_{1}}\right|^{(0)}+\left.\Delta Y_{2}{ }^{(0)} \frac{\partial G_{1}}{\partial Y_{2}}\right|^{(0)}+\cdots \\
& B_{2}=G_{2}\left(Y_{1}{ }^{(0)}, Y_{2}{ }^{(0)}\right)+\left.\Delta Y_{1}{ }^{(0)} \frac{\partial G_{2}}{\partial Y_{1}}\right|^{(0)}+\left.\Delta Y_{2}{ }^{(0)} \frac{\partial G_{2}}{\partial Y_{2}}\right|^{(0)}+\cdots \\
& V_{D}=\left|V_{D}\right|<\delta_{D} ; V_{n}=\left|V_{n}\right|<\delta_{n} ; Y_{D n}=|Y k n|<\theta_{D n} .
\end{aligned}
$$

Higher order partial derivatives are neglected. In matrix form equations (5) and (6) are shown as

$$
\left[\begin{array}{c}
B_{1}-G_{1}\left(Y_{1}{ }^{(0)}, Y_{2}{ }^{(0)}\right) \\
B_{2}-G_{2}\left(Y_{1}{ }^{(0)}, Y_{2}{ }^{(0)}\right)
\end{array}\right]=\left[\begin{array}{ll}
\frac{\partial G_{1}}{\partial Y_{1}} & \frac{\partial G_{1}}{\partial Y_{2}} \\
\frac{\partial G_{2}}{\partial Y_{2}} & \frac{\partial G_{2}}{\partial Y_{2}}
\end{array}\right]\left[\begin{array}{l}
\Delta Y_{1}{ }^{(0)} \\
\Delta Y_{2}{ }^{(0)}
\end{array}\right]
$$

$G_{1}\left(Y_{1}{ }^{(0)}, Y_{2}{ }^{(0)}\right)$ is the calculated value of $L_{1}$ for the assessed values of $Y_{1}{ }^{(0)}$ and $Y_{2}{ }^{(0)}$. If $\Delta B_{1}{ }^{(0)}$ is selected as the specified value of $B_{1}$ minus the calculated value of $B_{1}$ and also for $\Delta B_{2}{ }^{(0)}$,

$$
\left[\begin{array}{c}
\Delta B_{1}{ }^{(0)} \\
\Delta B_{2}{ }^{(0)}
\end{array}\right]=J^{(0)}\left[\begin{array}{l}
\Delta Y_{1}{ }^{(0)} \\
\Delta Y_{2}{ }^{(0)}
\end{array}\right] .
$$

Voltage at any bus $D$ for $N$ buses is shown as

$$
V_{D}=\frac{1}{Y_{D D}}\left[\frac{P_{D}-J Q_{D}}{V_{D}^{*}}-\sum_{n=1}^{N} Y_{D n} V_{n}\right]
$$

Here $P_{\mathrm{D}}$ and $Q_{\mathrm{D}}$ are denoted active and reactive powers. Moreover, equation (9) can be further extended as

$$
P_{D}-j Q_{D}=\left(Y_{D D} V_{D}+\sum_{n=1}^{N} Y_{D n} V_{n}\right) V_{D}{ }^{*} n \neq D \text {. }
$$

If $n=D$ then equation (10) is reduced to

$$
\begin{aligned}
P_{D}-j Q_{D} & =V_{D}^{*} \sum_{n=1}^{N} Y_{D n} V_{n}, \\
P_{D} & =V_{D}^{*} \sum_{n=1}^{N} Y_{D n} V_{n}, \\
Q_{D} & =-\operatorname{Img}\left\{V_{D}^{*} \sum_{n=1}^{N} Y_{D n} V_{n}\right\} .
\end{aligned}
$$

Equation (13) evaluates reactive power $Q_{D}$ for better prior voltage values at the buses, and Reactive Power $Q_{D}$ is substituted in equation (10) to obtain a new $Y_{D}$. In polar form, voltage at bus and line admittance is given as
Substituting equation (14) in (11),

$$
\begin{aligned}
P_{D}-j Q_{D} & =\sum_{n=1}^{N} Y_{D n} V_{n}<\theta_{D n}+\delta_{n}-\delta_{D}, \\
P_{D} & =\sum_{n=1}^{N} Y_{D n} V_{n} \operatorname{Cos}\left(\theta_{D n}+\delta_{n}-\delta_{D}\right) .
\end{aligned}
$$

And

$$
Q_{D}=-\sum_{n=1}^{N} Y_{D n} V_{n} \operatorname{Sin}\left(\theta_{D n}+\delta_{n}-\delta_{D}\right)
$$

Comparing equation (8) with power system,

$$
\begin{aligned}
& \Delta B_{1}{ }^{(0)}=\Delta P_{D}=P_{D \text { Spec }}-P_{D \text { Calc }}, \\
& \Delta B_{2}{ }^{(0)}=\Delta Q_{D}=Q_{D S p e c}-Q_{D C a l c}, \\
& \Delta Y_{1}^{(0)}=\Delta \delta_{D}{ }^{(0)} \\
& \Delta Y_{2}{ }^{(0)}=\left|V_{D}{ }^{(0)}\right|
\end{aligned}
$$

The partial derivative of real and reactive power is contained in the Jacobian " $J "$.

3.1. Fitness Function. The solution is obtained from the benefit of DG units injection measured by the reduction of losses and the operational and investment costs acquired in the DG unit injection. The function is defined as

$$
F=\frac{\operatorname{Benefit}(A)}{\text { Total } \operatorname{Cost}(X)}
$$

where

Benefit $(A)=$ Losses Cost before DG injection-Losses Cost after DG injection

Total Cost $(X)=$ Investment Cost + Injection Cost+ Maintenance Cost

Losses Cost $=$ Cost $/ \mathrm{kW} x$ Losses $(\mathrm{kW})$ 


\section{Distributed Generation Units Modelling and Test Cases}

To ensure that realistic data is used in the Electrical Transient Analyzer Program (ETAP) analysis, the residential feeder of $11 \mathrm{KV}$ Abdul Rehman Baba Feeder Peshawar, Pakistan, was chosen as the case study in this research work. ETAP software is used to study and model the chosen radial feeder because it is one of the most modern and dependable software tools for designing, operating, and planning an electrical power system. In this study, two different types of DG units are used: synchronous and induction generators. To offer a full examination, these units are injected and studied under various cases. The following test cases are considered for the analysis.

4.1. Without Distributed Generation Unit. In this particular case, the model of $11 \mathrm{KV}$ Abdul Rehman Baba Feeder is designed into ETAP software as the main source of electrical power and is at a considerable distance from the load. This is the base model, without any DG units, that is assessed for the original circuit, as illustrated in Figure 4.

These data are then used as a baseline against which different situations are evaluated, such as the inclusion of various types of DG units, their placement, and size. The comparison's major goal is to quantify the reduction of PLs and improvement of voltage profile in the distributed power system. Practically acquired data and results will be used for understanding the other cases. Sum of real and reactive PLs for the base case is shown in Table 1.

\subsection{By Injecting Synchronous Distributed Generation Unit.} In this case, the DG unit is being integrated with a system that will only deliver active power or act as a power source with a power factor of unity. This sort of DG will be deployed at various points along the feeder and examined for system power losses. Two subcases are formed by the installation of a synchronous generator serving as a DG unit with a producing capacity of $2.5 \mathrm{MW}$ at separate locations:

(1) First, as illustrated in Figure 5, this synchronous generator will be attached to bus bar 3 as a DG unit. In Table 2 real and reactive power losses are shown for this subcase.

(2) Secondly, it will be connected to bus bar 6 as shown in Figure 6. In Table 3 real and reactive power losses are shown for such subcase. It can be seen that power losses are much reduced when DG is injected at bus bar 6 than in the previous subcase. When DG is injected at bus bar 3 one bus bar is in critical condition while when injecting DG at bus bar 6 no bus bar is in critical conditions. So, voltage profile is also improved when DG is injected at bus bar 6 .

4.3. By Injecting Induction Distributed Generation Unit. DG unit in this case will be injected in the system and induce some reactive power along with the provision of active power. DG unit of proper size is inserted in the system at specific locations for analysis purposes. This DG unit will work as an induction machine in its general operation. The analysis for power losses will be taken into consideration afterwards. In this case, an induction generator with the same capacity, i.e., $2.5 \mathrm{MW}$ and a lagging PF of 0.85 , will be put at various places or buses across the distribution system. For the installation of such a DG unit (similar to synchronous DG), two alternative locations are chosen:

(1) At first, this DG is installed at bus bar 3 as shown in Figure 7. In Table 4 real and reactive power losses are shown. It can be seen that power losses are much increased when induction generator is injected, as compared to the situation when synchronous generator was injected alone at bus bar 3 or when no DG was installed.

(2) The same DG unit will be installed at bus bar 6 as shown in Figure 8. In Table 5 real and reactive power losses are shown. It can be seen that power losses are much increased when DG is injected at bus bar 6, compared to bus bar 3. When DG is injected at bus bar 3 one bus bar is in critical condition while when injecting DG at bus bar 6 no bus bar is in critical conditions. So, voltage profile is improved when DG is injected at bus bar 6 .

\section{Results and Discussion}

5.1. Power Losses Analysis. The kind of DG employed, as well as the location of installation in the power system, affects power losses; i.e., when a $2.5 \mathrm{MW}$ synchronous generator is installed at bus bar 6, the power losses are the lowest. Similarly, when induction generator of $2.5 \mathrm{MW}$ is injected at bus bar 6 maximum losses have been noticed. The following cases show different types of losses which were observed in this analysis.

5.1.1. Case I. In this particular case no DG has been integrated with the grid. The total power losses occurring in this case were found to be $399.7 \mathrm{~kW}$ and can be called active power losses as shown in Figure 9. The impedance of different lines, connection losses, and other types, i.e., transformer losses, contribute to the total losses. This is considered as the baseline to compare the results after the integration of an additional DG.

5.1.2. Case II. Case II is divided into two scenarios: in the first, a synchronous generator serving as a DG unit is injected at bus bar 3, while in the second, the identical synchronous generator is injected at bus bar 6. Power losses in the later subcase is reduced up to great extent as shown in Figure 10 which compares the two subcases with the Case I (with no additional DG installed).

5.1.3. Case III. Case III, like the previous two cases, is divided into two situations. The induction generator is installed at bus bar 3 in the first scenario, and it is integrated with the grid through bus bar 6 in the second scenario. The grid and the DG unit both feed the load. Taking power losses into consideration, installation of induction DG at bus bar 3 is a better option than at bus bar 6 as shown in Figure 11. But 


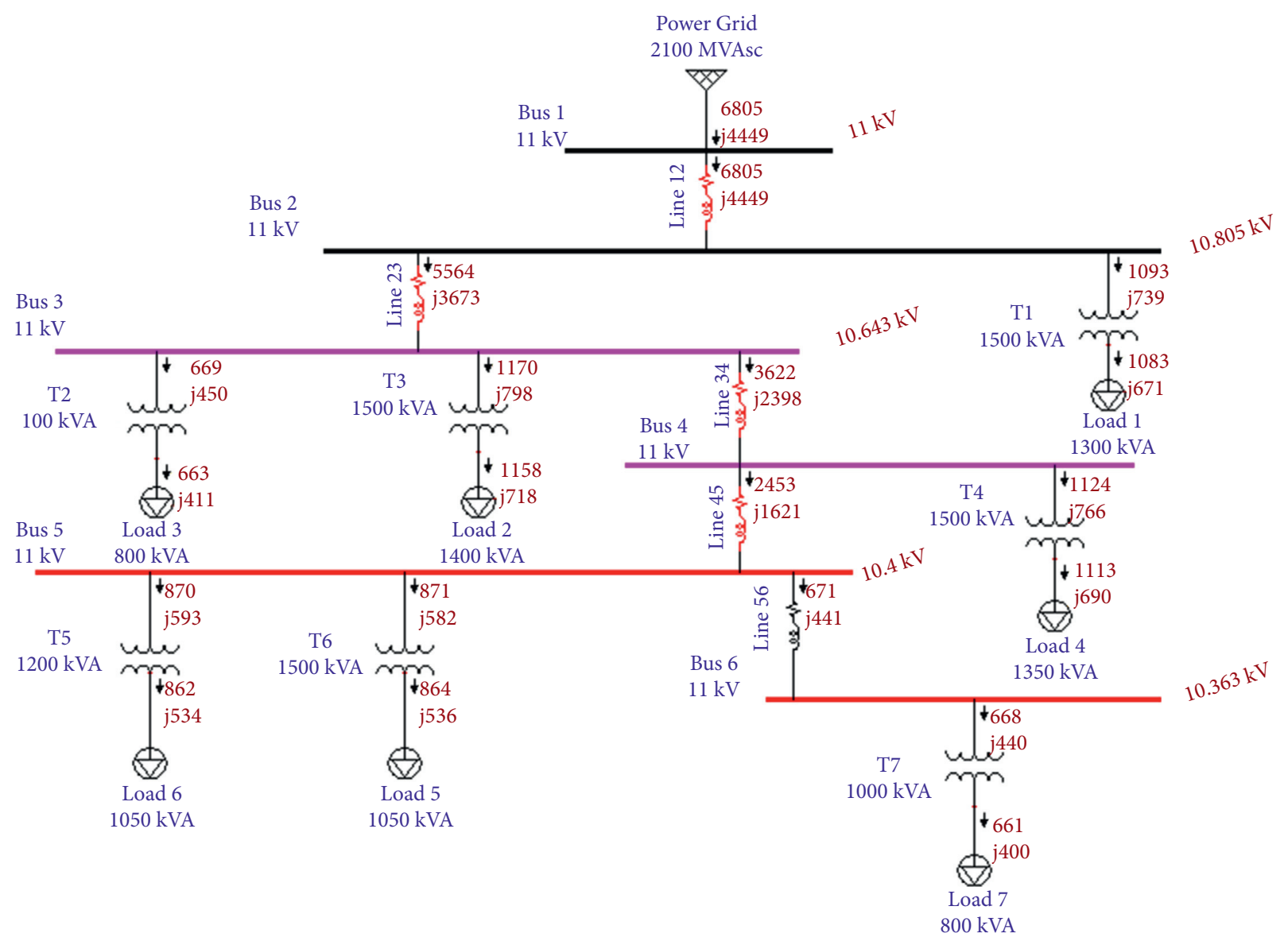

FIGURE 4: Without DG unit.

Table 1: Power losses with no DG unit [23].

\begin{tabular}{lcc}
\hline Branch/circuit ID & & Losses \\
& KW & 37.4 \\
Line 12 & 147.8 & 26.1 \\
Line 23 & 103.0 & 67.8 \\
T1 & 9.7 & 11.4 \\
Line 34 & 45.1 & 39.1 \\
T2 & 6.3 & 80.6 \\
T3 & 11.4 & 6.1 \\
Line 45 & 41.2 & 75.9 \\
T4 & 10.8 & 0.5 \\
Line 56 & 3.1 & 58.3 \\
T5 & 8.3 & 46.2 \\
T6 & 6.5 & 40.6 \\
T7 & 6.5 & 489.9 \\
Total & 399.7 & \\
\hline
\end{tabular}

both subcases of the Case III produce more power losses than the base case with no DG installed.

\subsection{Voltage Profile Analysis}

5.2.1. Case I. No DG unit is injected in this case. Voltage profile is decreased due to line impedance from source to load as shown in Figure 12.
5.2.2. Case II. In this case $2.5 \mathrm{MW}$ synchronous generator is used as a DG unit and injected at two locations, i.e., at bus bar 3 and bus bar 6 . A significant result is analyzed when DG is injected at bus bar 6 as shown in Figure 13.

5.2.3. Case III. In this case $2.5 \mathrm{MW}$ induction generator is used as a DG unit and injected at two locations, i.e., at bus bar 3 and bus bar 6. DG unit injection at bus bar 6 shows 


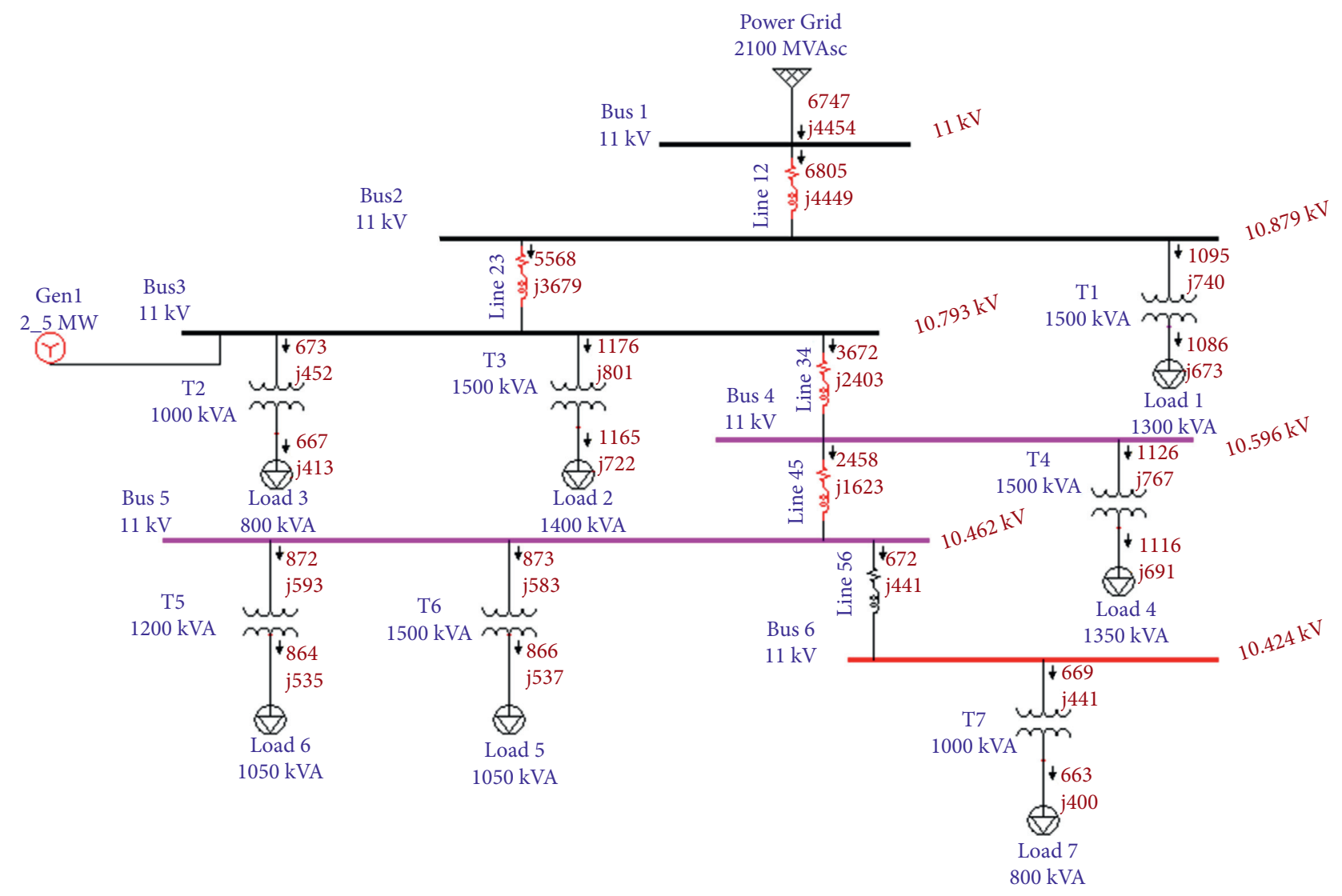

FIGURE 5: With synchronous DG unit at bus bar 3.

TABle 2: Power losses with synchronous generator at bus bar 3 .

\begin{tabular}{lcc}
\hline Branch/Circuit ID & & Losses \\
& KW & KVAR \\
\hline Line 12 & 83.6 & 35.1 \\
Line 23 & 47.5 & 23.5 \\
T1 & 9.6 & 67.2 \\
Line 34 & 87.4 & 12.9 \\
T2 & 6.2 & 38.4 \\
T3 & 11.2 & 79.1 \\
Line 45 & 40.9 & 6.0 \\
T4 & 10.7 & 75.3 \\
Line 56 & 3.1 & 0.5 \\
T5 & 8.2 & 57.8 \\
T6 & 6.5 & 45.8 \\
T7 & 6.4 & 40.2 \\
Total & 321.3 & 481.8 \\
\hline
\end{tabular}




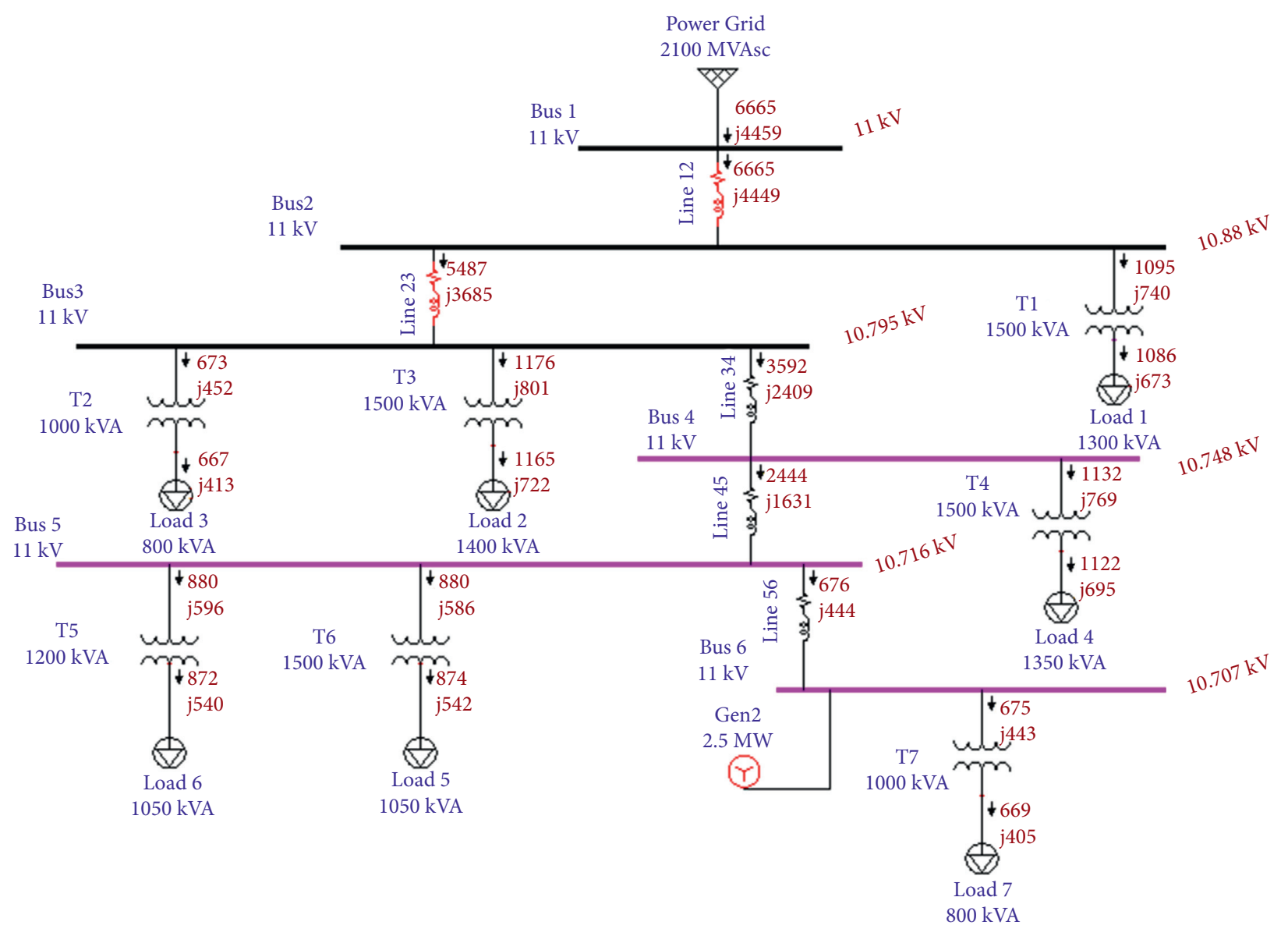

Figure 6: With synchronous DG unit at bus bar 6 .

TABle 3: Power losses with synchronous generator at bus bar 6 .

\begin{tabular}{lcc}
\hline Branch/circuit ID & & Losses \\
& KW & KVAR \\
Line 12 & 82.3 & 34.5 \\
Line 23 & 46.6 & 23.1 \\
T1 & 9.6 & 67.2 \\
Line 34 & 16.1 & 9.7 \\
T2 & 6.1 & 38.4 \\
T3 & 11.2 & 79.1 \\
Line 45 & 7.5 & 4.5 \\
T4 & 10.5 & 73.8 \\
Line 56 & 0.6 & 0.3 \\
T5 & 7.9 & 56.0 \\
T6 & 6.3 & 44.4 \\
T7 & 6.2 & 38.8 \\
Total & 210.9 & 469.8 \\
\hline
\end{tabular}




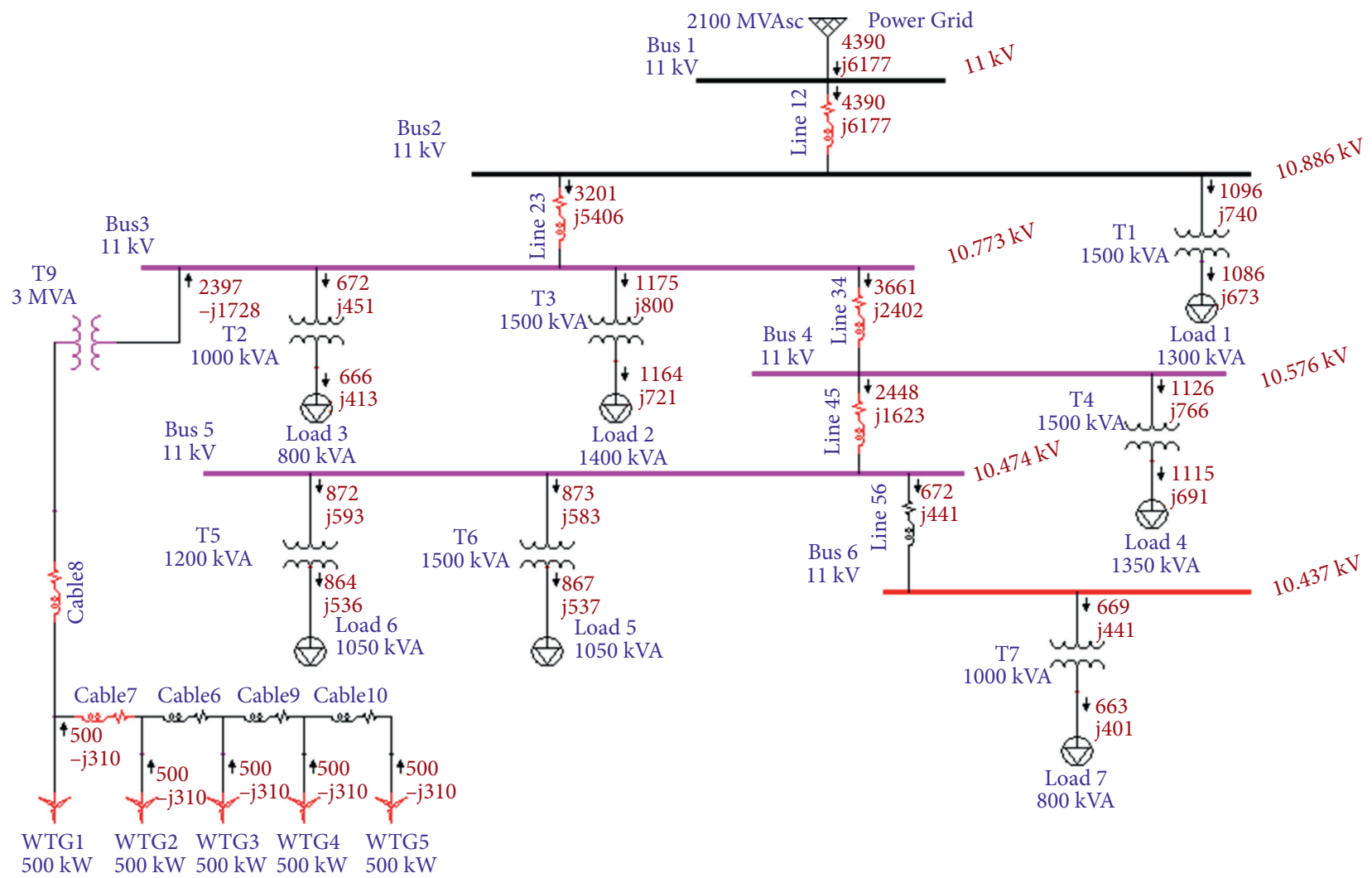

FIgURE 7: Installing induction DG unit at bus 3.

TABle 4: Power losses of the system for injecting induction generator at bus bar 3 .

\begin{tabular}{lcc}
\hline Branch/circuit ID & & Losses \\
& KW & 30.8 \\
Line 12 & 92.9 & 22.8 \\
Line 23 & 90.1 & 67.2 \\
T1 & 9.6 & 12.9 \\
Line 34 & 87.4 & 38.5 \\
T2 & 6.2 & 79.3 \\
T3 & 11.2 & 166.2 \\
T10 & 15.6 & 5.9 \\
Line 45 & 39.8 & 5.7 \\
T4 & 30.2 & 75.5 \\
Line 56 & 10.7 & 3.7 \\
T5 & 25.3 & 0.5 \\
T6 & 3.1 & 57.8 \\
T7 & 8.2 & 45.7 \\
Cable 11 & 6.5 & 2.1 \\
Cable 12 & 14.2 & 40.2 \\
Cable 13 & 6.4 & 0.9 \\
Cable 14 & 6.3 & 0.2 \\
Cable 15 & 1.6 & 655.9 \\
Total & 465.3 & \\
\hline
\end{tabular}




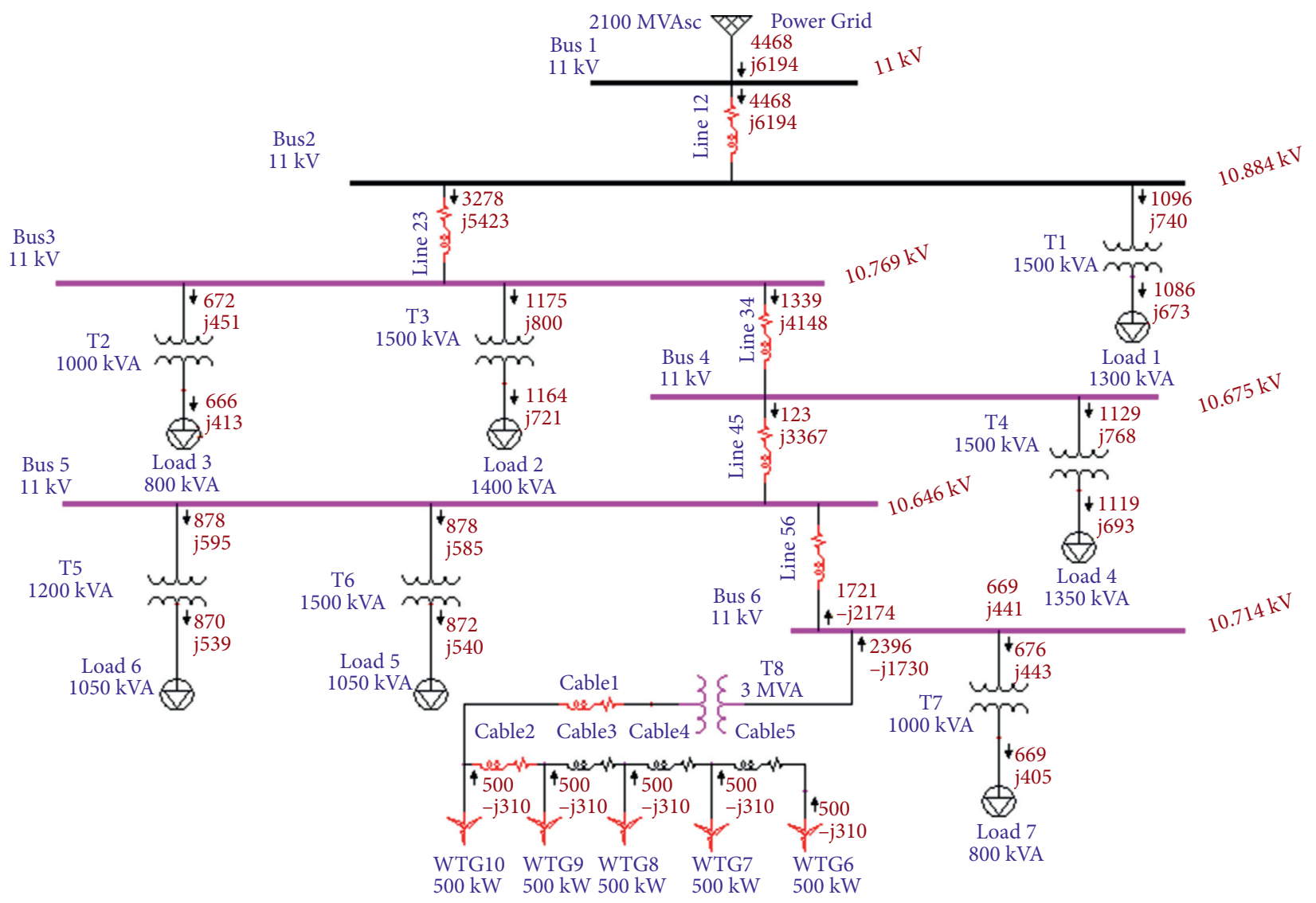

FIGURE 8: Installing induction DG unit at bus 6.

TABle 5: Power losses of the system with induction generator at bus bar 3 .

\begin{tabular}{lcc}
\hline Branch/circuit ID & & Losses \\
& KW & 31.3 \\
Line 12 & 94.4 & 23.2 \\
Line 23 & 91.7 & 67.2 \\
T1 & 9.6 & 12.8 \\
Line 34 & 86.6 & 38.5 \\
T2 & 6.2 & 79.3 \\
T3 & 11.2 & 7.8 \\
T10 & 52.7 & 74.5 \\
Line 45 & 10.6 & 5.2 \\
T4 & 35.4 & 56.5 \\
Line 56 & 8.0 & 44.7 \\
T5 & 6.3 & 38.7 \\
T6 & 6.2 & 168.1 \\
T7 & 15.8 & 5.9 \\
Cable 11 & 40.2 & 3.8 \\
Cable 12 & 25.6 & 2.1 \\
Cable 13 & 14.3 & 0.9 \\
Cable 14 & 6.3 & 0.2 \\
Cable 15 & 1.6 & 660.9 \\
Total & 522.8 & \\
\hline
\end{tabular}




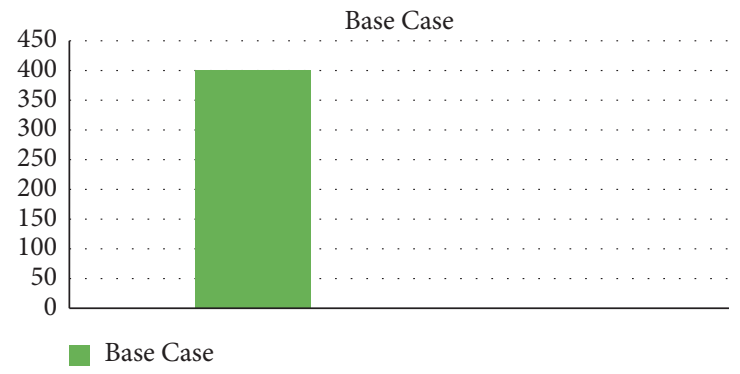

Figure 9: Total active power losses of the radial distribution system.

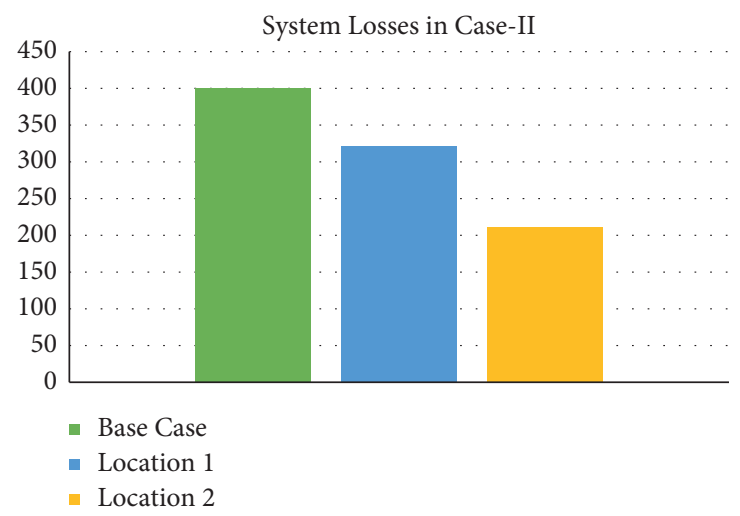

FIgURE 10: Power losses when synchronous generator is injected as a DG unit.

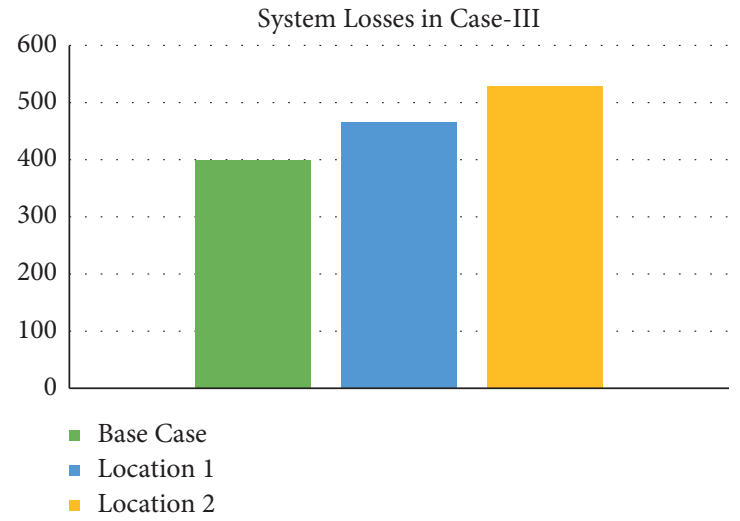

FIgURE 11: Power losses by injecting induction generator as a DG unit.

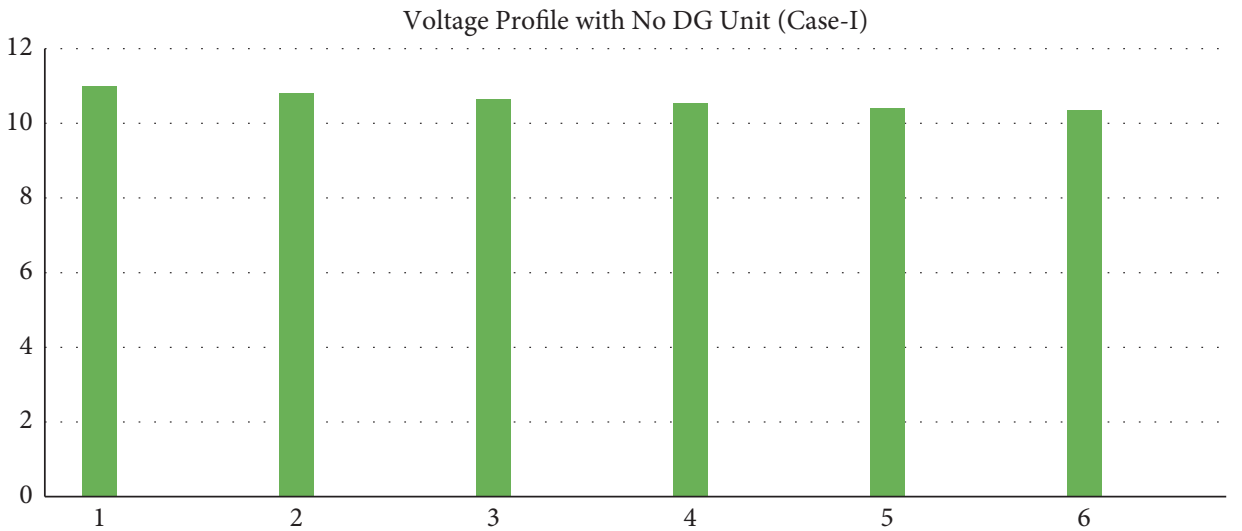

Base Case

FIgURe 12: Voltage profile of distribution system when no DG unit is injected. 


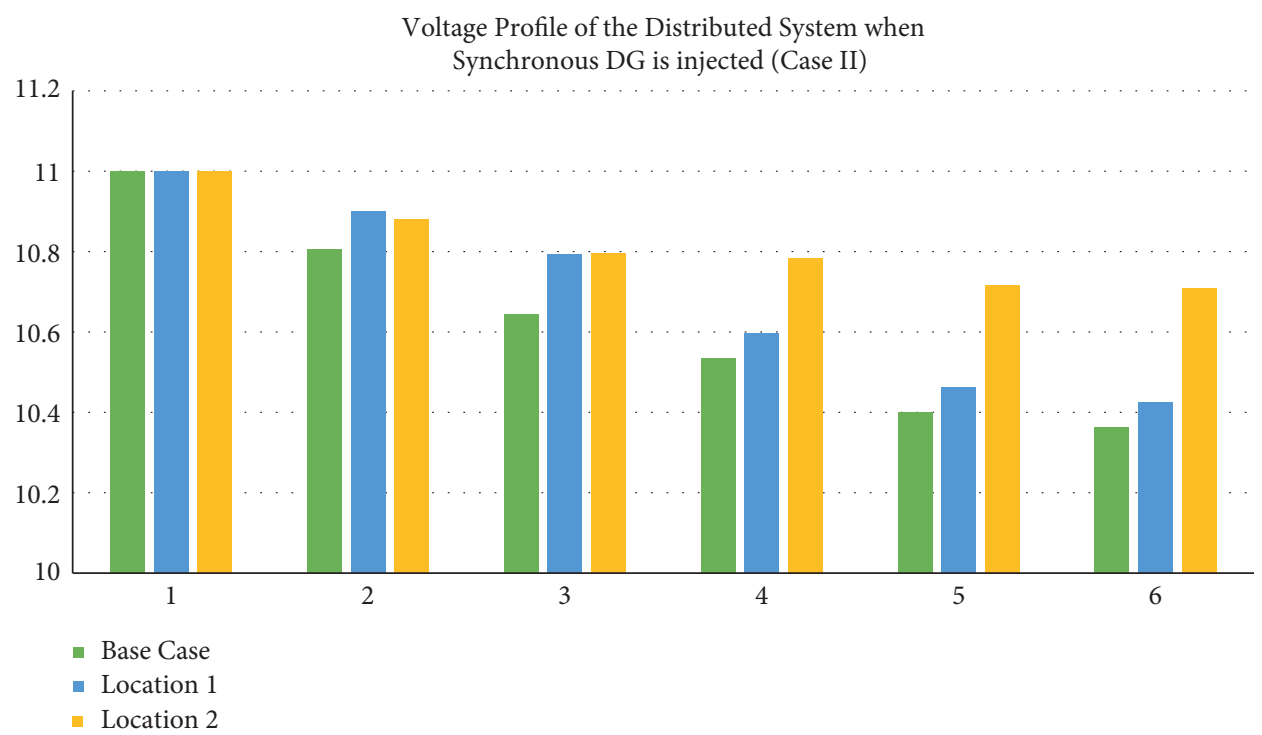

Figure 13: Voltage profile of distribution system when synchronous generator is injected as a DG unit.

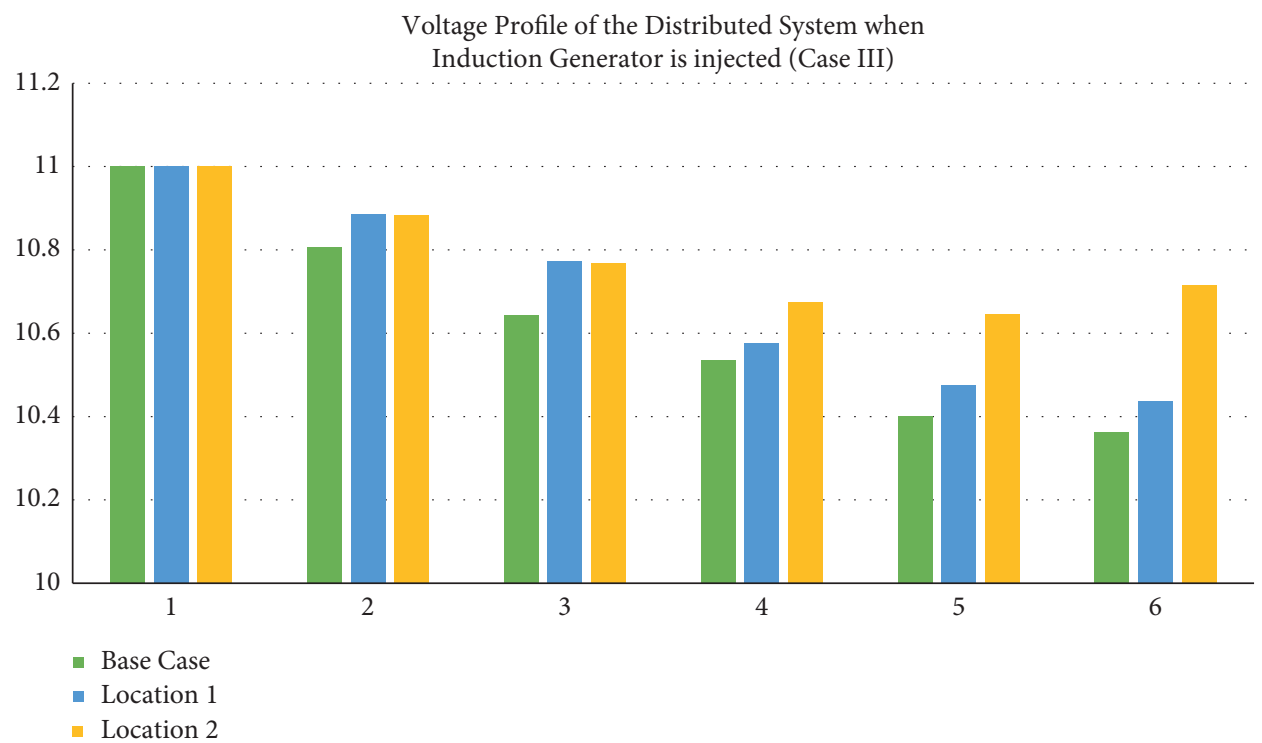

FIGURE 14: Voltage profile of distribution system when induction generator is injected as a DG unit.

better result comparing with bus bar 3 but not as good as the DG unit injected in Case II as shown in Figure 14.

\section{Conclusions}

Electrical power systems address the demand of large number of users through transmission of energy flows over long distances from the generating stations to the load centres using different channels. Power losses through these channels are a major concern as they overburden the power source and have extra cost to the consumers. This paper has presented a detailed analysis to tackle this issue by optimizing the integration of DG with a distribution network, with an objective to reduce power losses and improve power efficiency. Different cases are considered for different type of
DGs to perform a comprehensive comparison. To ensure the feasibility of the approach, experimental data from an $11 \mathrm{KV}$ grid station has been used to perform further simulations in ETAP software. The simulation analysis considered a base case with no additional DG installed, as a reference to produce $399.7 \mathrm{~kW}$ power losses, and results showed that installation of additional DG at properly calculated location, size, and type reduces the power losses to a great extent. It was also observed that synchronous generator helps in reduction of power losses but induction generator has the opposite effect. Injection of DG unit in DN causes voltage profile variation. Due to line impedance the end user faces a serious voltage rise and drop issues. Electrical equipment must run near the standard rated value; for this reason a better voltage profile will be maintained. This research 
focuses on the impact of DG in a radial DN and results were analyzed with and without DG considering voltage profile. It was concluded that injecting synchronous generator as a DG unit at bus bar 6 will have a better result on overall voltage profile of the system comparing with other cases. The useful results from this work can be used for the power system design in order to optimize the power losses and improve voltage profile for the distribution system.

\section{Data Availability}

All the data have been included in the study.

\section{Conflicts of Interest}

The authors declare no conflicts of interest.

\section{Acknowledgments}

This project was supported by the National Natural Science Foundation of China (61861043).

\section{References}

[1] A. A. Abdulrazzaq, M. Eremia, L. Toma, and C. A. Mandi, "Reconfiguration of distribution system with distributed generation using an adaptive loop approach," Journal of Electrical Engineering, vol. 70, no. 5, pp. 345-357, 2019.

[2] S. A. Kazmi and D. R. Shin, "DG placement in loop distribution network with new voltage stability index and loss minimization condition based planning approach under load growth," Journal of Energies, vol. 10, no. 8, p. 1203, 2017.

[3] M. Bhattacharya, S. Sivasubramani, and A. Roy, "Multiobjective placement and sizing of distributed generations in distribution system using global criterion method," International Transactions on Electrical Energy Systems, vol. 28, no. 1, p. e2471, 2018.

[4] p. p. Biswas, R. Mallipeddi, P. N. Suganthan, and G. A. J. Amaratunga, "A multiobjective approach for optimal placement and sizing of distributed generators and capacitors in distribution network," Applied Soft Computing, vol. 60, pp. 268-280, 2017.

[5] S. Kansal, B. Tyagi, and V. Kumar, "Cost-benefit analysis for optimal distributed generation placement in distribution systems," International Journal of Ambient Energy, vol. 38, no. 1, pp. 45-54, 2017.

[6] J. A. P. Lopes, N. Hatziargyriou, J. Mutale, P. Djapic, and N. Jenkins, "Integrating distributed generation into electric power systems: a review of drivers, challenges and opportunities," Electric Power Systems Research, vol. 77, no. 9, pp. 1189-1203, 2007.

[7] C. Zhang, J. Li, Y. J. Zhang, and Z. Xu, "Optimal location planning of renewable distributed generation units in distribution networks: an analytical approach," IEEE Transactions on Power Systems, vol. 33, no. 3, pp. 2742-2753, 2018.

[8] F. C. R. Coelho, I. C. da Silva Junior, B. H. Dias, and W. B. Peres, "Optimal distributed generation allocation using a new metaheuristic," Journal of Control, Automation and Electrical Systems, vol. 29, no. 1, pp. 91-98, 2018.

[9] M. A. Aman, S. Ahmad, B. Noor, and F. W. Karam, "Mitigating the adverse impact of un-deterministic distributed generation on a distribution system considering voltage profile," Engineering, Technology \& Applied Science Research, vol. 8, no. 3, pp. 2998-3003, 2018.

[10] C. Hari Prasad, K. Subbaramaiah, and P. Sujatha, "Cost-beneft analysis for optimal DG placement in distribution systems by using elephant herding optimization algorithm," Journal of Renewables: Wind, Water and Solar, vol. 6, no. 2, pp. 1-12, 2019.

[11] E. C. Ashigwuike and S. A. Benson, "Optimal location and sizing of distributed generation in distribution network using adaptive neuro-fuzzy logic technique," European Journal of Engineering Research and Science, vol. 4, no. 4, pp. 83-89, 2019.

[12] A. Sadiq, S. S. Adamu, and M. Buhari, "Optimal distributed generation planning in distribution networks: a comparison of transmission network models with FACTS," Engineering Science and Technology, an International Journal, vol. 22, no. 2, pp. 33-46, 2019.

[13] Y. Li, B. Feng, G. Li, J. Qi, D. Zhao, and Y. Mu, "Optimal distributed generation planning in active distribution networks considering integration of energy storage," Applied Energy, vol. 210, pp. 1073-1081, 2018.

[14] M. Mohammadi, A. M. Rozbahani, and S. Bahmanyar, "Power loss reduction of distribution systems using BFO based optimal reconfiguration along with DG and shunt capacitor placement simultaneously in fuzzy framework," Journal of Central South University, vol. 24, no. 1, pp. 90-103, 2017.

[15] U. Sultana, A. Khairuddin, A. S. Mokhtar, S. H. Qazi, and B. Sultana, "An optimization approach for minimizing energy losses of distribution systems based on distributed generation placement," Journal Teknologi, vol. 79, no. 4, pp. 87-96, 2017.

[16] M. C. V. Suresh and E. J. Belwin, "Optimal DG placement for benefit maximization in distribution networks by using dragonfy algorithm," Journal of Renewables: Wind, Water, and Solar, vol. 5, no. 1, pp. 1-8, 2017.

[17] S. S. Tanwar and D. K. Khatod, "Techno-economic and environmental approach for optimal placement and sizing of renewable DGs in distribution system," Energy, vol. 127, no. c, pp. 52-67, 2017.

[18] W. Warid, H. Hizam, N. Mariun, and N. I. Abdul-Wahab, "A sensitivity based methodology for optimal placement of distributed generation in meshed power systems," International Journal of Simulation. Systems, Science and Technology, vol. 17, no. 41, pp. 1-44, 2017.

[19] C. Yammani, S. Maheswarapu, and S. K. Matam, "Optimal placement and sizing of distributed generations using shuffled bat algorithm with future load enhancement," International Transactions on Electrical Energy Systems, vol. 26, no. 2, pp. 274-292, 2016.

[20] A. Uniyal and A. Kumar, "Optimal distributed generation placement with multiple objectives considering probabilistic load," Procedia Computer Science, vol. 125, pp. 382-388, 2018.

[21] M. Kashyap, S. Kansal, and B. P. Singh, "Optimal installation of multiple type DGs considering constant, ZIP load and load growth," International Journal of Ambient Energy, vol. 41, no. 14, pp. 1561-1569, 2018.

[22] S. Nawaz, D. A. K. Bansal, and D. M. P. Sharma, “A novel approach for multiple DG allocation in real distribution system," International Journal of Engineering and Technology, vol. 9, no. 2, pp. 963-968, 2017.

[23] M. A. Aman, S. Ahmad, A. U. Asar, and B. Noor, "Analyzing the diverse impacts of conventional distributed energy resources on distribution system," International Journal of Advanced Computer Science and Applications, vol. 8, no. 10, 2017. 